\title{
A STUDY ON THE TOXICITY OF NATURAL FOOD DYES - TOXICITY AND ENZYME INHIBITION IN PARAMECIUM CAUDATUM -
}

\author{
Fumiyo SAKO ${ }^{1)}$, Noriko KoBAYASHI ${ }^{21}$, Naoyuki TANIGUCHI ${ }^{3)}$ \\ and Eimatsu TAKAKUWA ${ }^{3)}$ \\ 1) Department of Home Economics, Hokkaido University of \\ Education, South 22 West 12, Sapporo 064, Japan, 2) Tenshi \\ Women's Junior College, North 13 East 3, Sapporo 065, Japan \\ and 3) Department of Hygiene and Preventive Medicine, \\ Hokkaido University School of Medicine, North 15 West 7, \\ Sapporo 060, Japan
}

Received February 2, 1978

\begin{abstract}
The toxicity of 14 commercial natural dyes which are widely used as food additives in Japan was studied on Paramecium caudatum. Laccaic acid and capsanthin were found to be very toxic to Paramecium caudatum. Some of the commercially available carminic acid and crocin were also toxic. The inhibitory effect of natural food dyes on leucine aminopeptidase, acid phosphatase and esterase in vitro was proportional to the toxic effect of the dyes on the survival time of Paramecium caudatum. Analyses of the commercial natural food dyes by high performance liquid chromatography failed to identify the toxic components.
\end{abstract}

Key words : toxicity, Paramecium caudatum, enzyme, HPLC

\section{INTRODUCTION}

A considerable attention has been paid to natural food dyes since last several years, and there has been a rapid increase in the quantity of natural food dyes used in Japan since most of the tar food dyes, which are synthetized chemically, are hepatotoxic or carcinogenic. However, no regulation or restriction on the law is now available for natural food dyes in Japan and little or no safety tests have been conducted.

Our previous report indicated that most of the tar food dyes, which were considered to be hepatotoxic or carcinogenic in mammalian tissues, showed a marked toxic effect on Paramecium caudatum (Pc), a unicellular animal, and they could serve as an indicator for the toxicity of tar food dyes (Sako et al., 1977).

In a bioassay system, a problematic point is whether the reaction of agents on Pc, which is a lower animal in the evolutionary scale than the rat and mouse, can be applied to higher animals. It can be postulated, however, that an agent that is toxic on Pc would

漙絡先： $\mathbf{T} 064$ 札幌市中央区南22条西12丁目 北海道教育大学 酒 向 史 代 
Fumiyo SAKO et al.

have some abnormal action on the tissues of higher animals.

Little works have been done on the effect of toxicity of food additives to Pc, however some reports are available in the literature on the sensitivity of $\mathrm{Pc}$ to caffeine (Joan, 1974), sodium 2, 4-D (Kokia, 1971), detergent enzyme (Cairns et al., 1971), aflatoxin B (Reiss, 1971), and insecticides (Takakuwa et al., 1971).

We also reported that the inhibitory effect of dyes on leucine aminopeptidase (LAP) and acid phosphatase in the extract of Pc cells was consistent with the toxic effect of the dyes on the survival time of Pc (Sako et al., 1976; Sako et al., 1977).

Tanaka and Okahara (1973) reported that some of the tar food dyes showed an extreme inhibitory effect on LAP activity and amino acid transport of rat small intestine. These authors proposed that the dyes have some effects on the digestive process or amino acid transport of the small intestine. Esteve (1970) found that acid phosphatase existed in food vacuoles, autophagic vesicles and dense bodies of $\mathrm{Pc}$, and was related to the digestive processes of Pc. It has also been shown that many esterases are present in the cytoplasm and food vacuoles of protozoa such as Tetrahymena (Allen et al., 1963) or Paramecium aurelia (Rowe et al., 1971). It is known that $\gamma$-glutamyl transpeptidase ( $\gamma$-GTP) plays an important role in the amino acid transport of mammalian tissues such as kidney (Orlowski and Meister, 1970) or tumor tissue (Taniguchi et al., 1975).

The present report describes the toxicity of 14 commercially available natural food dyes, using Pc as an indicator. Also, the effect of natural food dyes on the activities of LAP, acid phosphatase, $\gamma-\mathrm{GTP}$ and esterase described above was examined in vitro in order to investigate the mechanisms of interactions of natural food dyes with Pc. We also analysed the components of several natural food dyes by high performance liquid chromatography (HPLC).

\section{METHODS}

\section{Cultures of $P c$}

Pc was maintained at $22^{\circ} \mathrm{C}$ on $0.15 \%$ dried lettuce infusion and fed on Aerobacter aerogenes for five days before starting experiments.

\section{Determination of Survival Time}

Natural food dyes $(0.1 \mathrm{ml})$ of various concentration were put in a hollow slide glass (diameter; $22 \mathrm{~mm}$ ), and an equal volume of $0.04 \mathrm{M}$ phosphate buffer, $\mathrm{pH} 7.0$, was added. Aftar 5 to $10 \mathrm{Pc}$ were added to this slide glass, survival times of $2 \mathrm{Pc}$ that died initially were measured microscopically. The same method was tested from 5 to 6 times for each dye concentration. The measurement was continued for $20 \mathrm{~min}$. The survival time was difined as the time required until death was observed for each concentration. Death was assumed to have occurred when there was no observal movement.

Our previous report (Sako et al., 1977) indicated that following the lag phase the death rate increased exponentially, and the rate of death was almost linear when the number of deaths were plotted against time semilogarithmically. After the logarithmic 


\section{Toxicity of Natural Food Dyes}

phase, the death rate reached a stationary phase. It seems possible that the duration of the lag phase ( $\mathrm{La}$ ) and the slope of the death rate in the logarithmic phase (Lo) could be used as indicators of toxicity.

In this experiment La was obtained by the following method. Five to $10 \mathrm{Pc}$ were subjected to one dye solution and the survival times of the $2 \mathrm{Pc}$ which died initially were measured microscopically by the method described above. This experiment was carried out 5-6 times repeatedly on each dye concentration. The mean value was calculated from the $3 \mathrm{Pc}$ with the shortest survival times obtained. This was defined as La. Lo was defined as follows;

$\mathrm{Lo}=$ the numbers of $\mathrm{Pc}$ measured / the longest survival time-the shortest survival time

The concentration of dyes used in the bathing fluid was $0.5 \%$. This concentration is generally used in food in Japan. One \% solution of dyes was used in the case when $\mathrm{La}$ in $0.5 \%$ even after the lapse of $20 \mathrm{~min}$ was above $800 \mathrm{sec}$, and similarly $0.3 \%$ and $0.1 \%$ were used for the dyes in the case when La was found to be below $800 \mathrm{sec}$.

Preparation of Enzyme Extracts

The crude enzyme extracts were prepared as described previously (Sako et al., 1977). Assay of LAP, Acid Phosphatase, $\gamma-G T P$ and Esterase Activity

LAP, acid phosphatase and $\gamma$-GTP activity were assayed as described in our previous paper (Sako et al., 1977). Esterase activity in the Pc extract was measured using p-nitrophenyl acetate as substrate according to a slight modification of the method of Armstrong et al. (1966).

\section{Chromatography}

HPLC was carried out with a system consisting of a Waters Model 3000 pump, a Model U6K universal injector, with a $10 \times 1 / 4$ in. O.D. stainless steel column commercially packed with $\mu$ Bondapak $\mathrm{C}_{18}$ (Waters), and a Model $\mathrm{R} 401$ differential refractometer. Absorbance was measured at $254 \mathrm{~nm}$ using a Model 440 high sensitivity absorbance detector. Each dye was diluted with water, except for carminic acid "A" which was diluted with methanol. Details of the solvent systems used are described in the legends of the figures.

\section{Chemicals}

L-Leucine $p$-nitroanilide, $p$-nitrophenyl phosphate and L- $\gamma$-glutamyl $p$-nitroanilide were obtained from C.F. Boehringer, Mannheim, Yamanouchi, Japan. All other reagents used were of analytical grade.

Commercial natural food dyes tested were shown in Table 1. These dyes were obtained from the Tanabe Pharmacentical Co. Ltd, the Takasago Koryo Kogyo Co. Ltd, the Daito Co. Ltd, the Tokyo Kasei Co. Ltd and the Nihon Yoryokuso Co. Ltd.

\section{RESULTS}

\section{Effect of Natural Food Dyes on the Survival Time of Pc}

The effect of natural food dyes on the survival time of Pc was examined. The values 
Fumiyo SAKO et al.

Table 1. Natural food dyes used in this experiment

\begin{tabular}{|c|c|c|c|}
\hline chemical name & trivial name & color & source \\
\hline \multicolumn{4}{|l|}{$\langle$ Anthocyanins $\rangle$} \\
\hline \multirow[t]{2}{*}{ Enocyanin } & grape-skin & red & \\
\hline & extract & purplish red & \\
\hline \multicolumn{4}{|l|}{$\langle$ Anthraquinones〉 } \\
\hline Carminic acid $A^{*}$ & cochineal & "l & $\begin{array}{l}\text { extract from Coccus cacti } \\
\text { coccinelifera }\end{array}$ \\
\hline Carminic acid $B^{*}$ & 11 & "I & $" 1$ \\
\hline Laccaic acid $\mathrm{A}^{*}$ & lacc dye & "l & $\begin{array}{l}\text { extract from Laciffer Lacca } \\
\text { Kerr }\end{array}$ \\
\hline \multicolumn{4}{|l|}{$\langle$ Carotinoids $\rangle$} \\
\hline Capsanthin & paprika & orange-red & \\
\hline Crocin $A^{*}$ & & yellow & extract from Rubiaceae \\
\hline Crocin $\mathrm{B}^{*}$ & & "1 & 11 \\
\hline Crocin $\mathrm{C}^{*}$ & & blue & $\begin{array}{l}\text { produced with Rubiaceae } \\
\text { extract by an enzymatic } \\
\text { method }\end{array}$ \\
\hline Crocin $\mathrm{D}^{*}$ & & green & $\begin{array}{l}\text { added natural yellow dye to } \\
\text { Crocin C }\end{array}$ \\
\hline \multicolumn{4}{|l|}{$\langle$ Others $\rangle$} \\
\hline Monascoruburin & & red & $\begin{array}{l}\text { extract from Monascus } \\
\text { purpureus }\end{array}$ \\
\hline Epicatechin & cacao-bean dye & brown & $\begin{array}{l}\text { involving leucoanthocyanin } \\
\text { and catechin }\end{array}$ \\
\hline Betanin & beat red & red & \\
\hline Carthamin & & "I & $\begin{array}{l}\text { extract from Carthamus } \\
\text { Tinctoruius Linne }\end{array}$ \\
\hline
\end{tabular}

*A,B,C and D refer the product of $\mathrm{A}, \mathrm{B}, \mathrm{C}$ and $\mathrm{D}$ Co. Lid. respectively.

of $\mathrm{La}$ and Lo were listed in Table 2. Previous report indicated that $\mathrm{La}$ and Lo were well proportional to the survival times of $\mathrm{Pc}$, however in this experiment Lo was not well proportional to the survival times, therefore the order of the toxicity was estimated for the La values.

Laccaic acid "A", laccaic acid "B" and carminic acid "A", which belong to anthraquinone group, were remarkably toxic to $\mathrm{Pc}$. On the other hand carminic acid " $\mathrm{B}$ ", which belongs to the same group, was not toxic. Capsanthin and crocin "B", which belong to carotinoid group, were also toxic to $\mathrm{Pc}$, while other crocins (crocin "A, C and D") were not toxic. The toxicities of enocyanin and carthamin, both of which are widely used in Japan were of intermediate strength.

From these results, the toxicity of natural food dyes on $\mathrm{Pc}$ was found to be in the order of laccaic acid "B">laccaic acid "A">capsanthin $>$ carminic acid "A">crocin "B" $>$ monascoruburin $>$ epicatechin $>$ enocyanin $>$ betanin $>$ carthamin $>$ carminic acid " $B$ ", crocin "A", crocin "C" and crocin "D". 
Toxicity of Natural Food Dyes

Table 2. Effect of natural food dyes on the survival of Paramecium caudatum

\begin{tabular}{|c|c|c|c|c|c|c|c|c|}
\hline \multirow{2}{*}{ Natural food dyes } & \multicolumn{2}{|r|}{$1.0 \%$} & \multicolumn{2}{|r|}{$0.5 \%$} & \multicolumn{2}{|c|}{$0.3 \%$} & \multicolumn{2}{|c|}{$0.1 \%$} \\
\hline & $\mathrm{La}$ & Lo & $\mathrm{La}$ & Lo & $\mathrm{La}$ & Lo & $\mathrm{La}$ & Lo \\
\hline Enocyanin & 124 & $4.69 \times 10^{-2}$ & a & & & & & \\
\hline Carminic acid $\mathrm{A}$ & & & 20 & 1.43 & 575 & $1.59 \times 10^{-2}$ & a & \\
\hline Carminic acid B & a & & $\mathrm{a}$ & & & & & \\
\hline Laccaic acid $A$ & & & 405 & $4.17 \times 10^{-2}$ & 483 & $1.27 \times 10^{-2}$ & 767 & \\
\hline Laccaic acid B & & & 183 & $1.11 \times 10^{-1}$ & 365 & $2.10 \times 10^{-2}$ & 476 & $1.57 \times 10^{-2}$ \\
\hline Capsanthin & & & $\mathrm{b}$ & & $\mathrm{b}$ & & 798 & $1.70 \times 10^{-2}$ \\
\hline Crocin A & a & & $\mathrm{a}$ & & & & & \\
\hline Crocin B & & & 713 & & a & & & \\
\hline Crocin $\mathrm{C}$ & a & & $\mathrm{a}$ & & & & & \\
\hline Crocin D & $\mathrm{a}$ & & $\mathrm{a}$ & & & & & \\
\hline Monascoruburin & 186 & $6.56 \times 10^{-2}$ & 864 & & & & & \\
\hline Epicatechin & 441 & $4.85 \times 10^{-2}$ & 1127 & & & & & \\
\hline Betanin & 624 & $3.22 \times 10^{-2}$ & $\mathrm{a}$ & & & & & \\
\hline Carthamin & 850 & & a & & & & & \\
\hline
\end{tabular}

La: the duration of lag phase (time in sec)

Lo: the slope of logarithmic phase (the numbers of Pc measured/ sec)

a : no death was observed for $20 \mathrm{~min}$

b : impossible to observe microscopically because of high concentration

Table 3. Effect of food dyes on activities of leucine aminopeptidase, acid phosphatase, $\gamma$-glutamyl transpeptidase and esterase extracted from Paramecium caudatum This experiment was carried out by adding a solution of food dyes to the standard reaction mixture. The concentration of food dyes employed was $0.1 \%$ except for the concentration of laccaic acid " $\mathrm{B}$ " and carminic acid "A" which was $0.05 \%$.

\begin{tabular}{lcccc}
\hline \multirow{2}{*}{ Natural food dyes } & \multicolumn{4}{c}{ relative enzyme activity $(\%)$} \\
\cline { 2 - 5 } & $\begin{array}{l}\text { leucine } \\
\text { aminopeptidase }\end{array}$ & $\begin{array}{l}\text { acid } \\
\text { phosphatase }\end{array}$ & $\begin{array}{l}\gamma \text {-glutamyl } \\
\text { transpeptidase }\end{array}$ & esterase \\
\hline Carminic acid A & 10 & 22 & 0 & 3 \\
Laccaic acid B & 15 & 13 & 0 & 4 \\
Epicatechin & 45 & 49 & 104 & 61 \\
Enocyanin & 63 & 100 & 134 & 99 \\
Crocin A & 81 & 71 & 86 & 104 \\
Carminic acid B & 77 & 77 & 87 & 116 \\
\hline
\end{tabular}

Each value represents the average of closely agreeing duplicate analyses.

Effect of Natural Food Dyes on LAP, Acid Phosphatase, $\gamma-G T P$ and Esterase Activity

The effect of natural food dyes on these enzyme activities was assayed in vitro, in order to investigate the toxic mechanism of natural food dyes. The results were shown in Table 3. Two dyes were selected respectively from the natural food dyes with the high, medium and low grade of the toxic order as mentioned avove. 
Laccaic acid "B" and carminic acid "A" which showed high toxic effects on Pc inhibited these enzyme activities almost completely. Epicatechin, the toxicity of which was found to be intermediate, had no inhibitory effect on $r$-GTP activity which was reported to play an important role in the amino acid transport. However, a significant inhibition was observed on the other enzymes which was supposed to play important roles in the digestive process of Pc. Enocyanin which showed an intermediate toxicity on $\mathrm{Pc}$ as in the case of epicatechin showed a slight inhibition of LAP activity, while no inhibitory effect of the other enzyme activities was seen, and thus it was assumed that this dye had a complicated toxic mechanism. These four enzyme activities were scarcely inhibited by crocin "A" and carminic acid "B" which were not toxic to Pc.

HPLC Anaiyses of Carminic Acid " $A$ ", Carminic Acid " $B$ ", Crocin " $A$ " and Crocin “ $B$ "

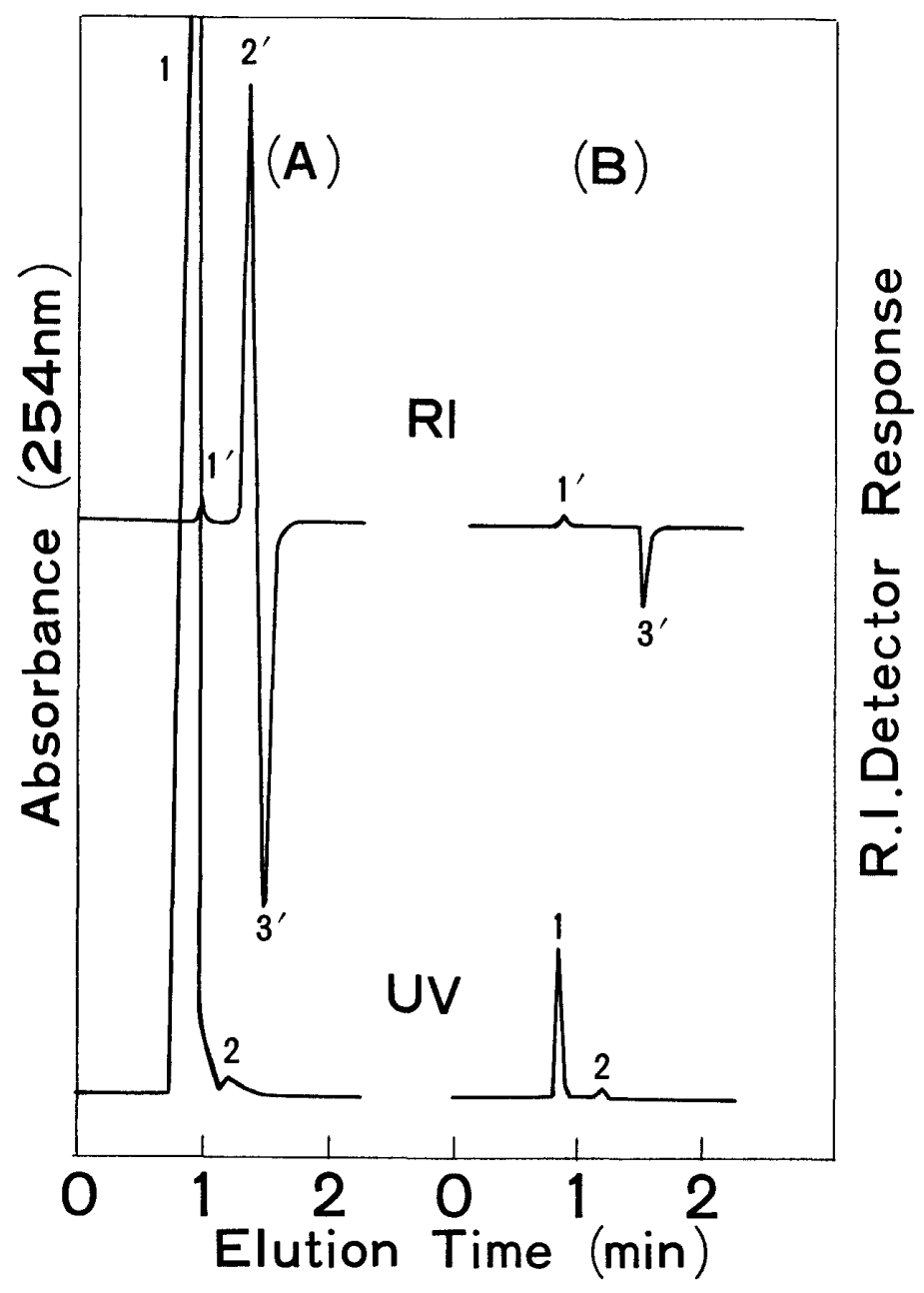

Fig. 1. HPLC Separation of carminic acid " $A$ " and carminic acid " $B$ " on $\mu$ Bondapak $\mathrm{C}_{18}(10 \times 1 / 4 \mathrm{in}$.) in acetonitrile-water $(1: 2)$ at a flow-rate of $2.2 \mathrm{ml} / \mathrm{min}$. Each injection corresponds to $15 \gamma$ of the original sample. Detector: UV 2.0 AUFS, RI 64X (A) carminic acid "A"; (B) carminic acid "B" 


\section{Toxicity of Natural Fond Dyes}

The toxicity of carminic acid "A" on Pc was found to be remarkable compared to carminic acid " $\mathrm{B}$ " as described above. In order to examine the difference in the toxicity, these dyes were subjected to the column of HPLC.

As shown in Fig. 1, two peaks both in carminic acid " $\mathrm{A}$ " and carminic acid " $\mathrm{B}$ " were separated by a UV detector. However, the quantity of the main component (peak 1) was quite different. Also, carminic acid " $B$ " had no peak 2' which was detected in carminic acid "A" using a differential refractometer. Carminic acid, which was commercially available as a chemical reagent, was also loaded on the HPLC. The elution pattern of this reagent was identical with that of carminic acid "A", even though no toxicity of this reagent was observed on Pc. It seems that the peak 1 and peak 2 ' had no relation to the toxic effect on Pc. No different component was noted between crocin " $\mathrm{A}$ " and crocin " $\mathrm{B}$ " by both detectors as shown in Fig. 2, though some difference in the quantity of peak 2' was observed. It was uncertain whether or not peak 2' had the toxic effect on Pc.

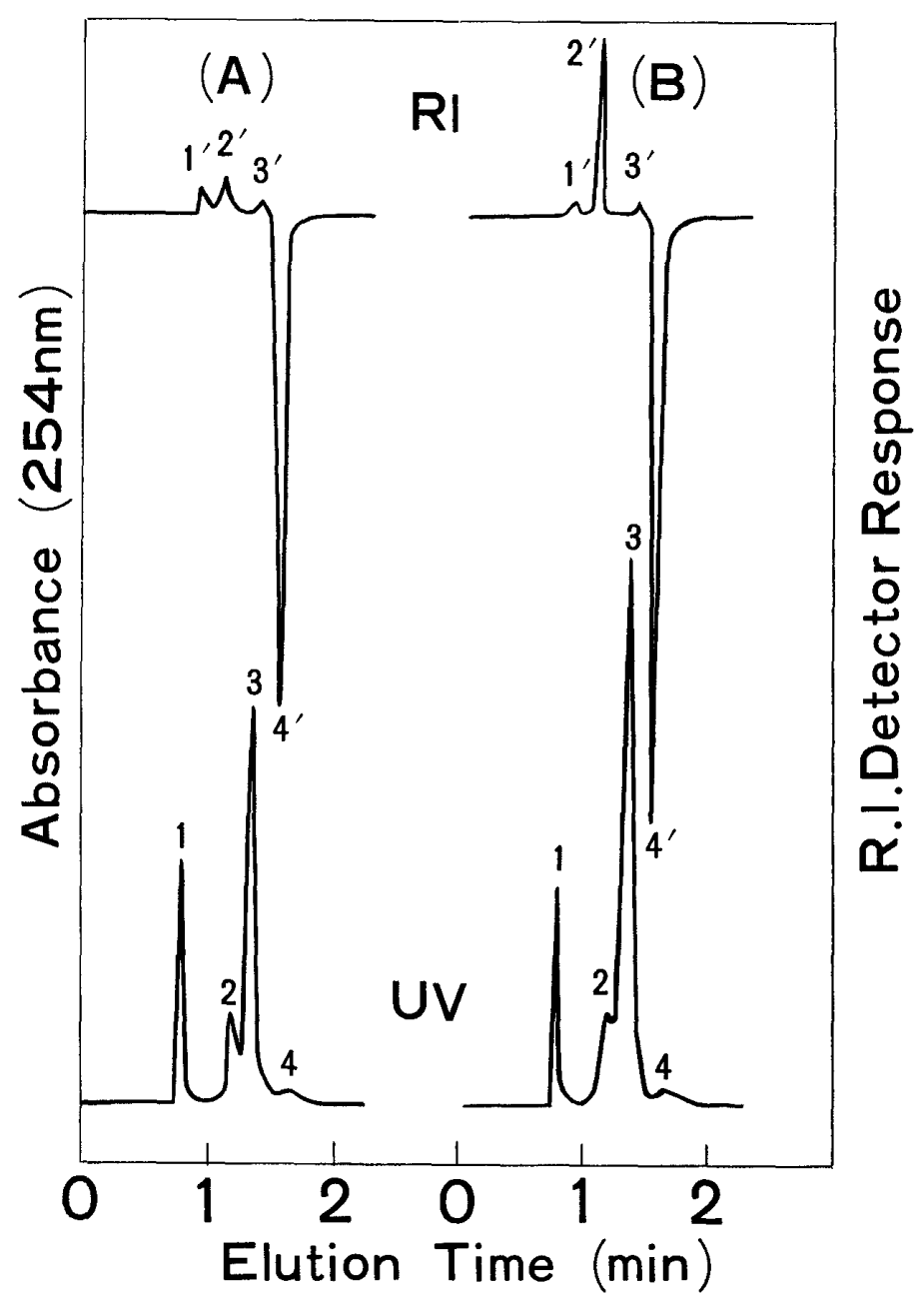

Fig. 2. HPLC Separation of crocin " $A$ " and crocin " $B$ " on $\mu$ Bondapak $\mathrm{C}_{18}(10 \times 1 / 4$ in. $)$ in acetonitrile-water $(1: 2)$ at a flow-rate of $2.2 \mathrm{ml} / \mathrm{min}$. Each injection corresponds to $40 \gamma$ of the original sample. Detector: UV 0.5 AUFS, RI 32X (A) crocin "A"; (B) crocin "B" 


\section{DISCUSSION}

Among the natural food dyes used in this experiment, the dyes which were extracted from the insect such as laccaic acid and one of the carminic acid examined were more toxic than those extracted from plants. Laccaic acid which was especially toxic had never been used as food additives in the past, but it is reported to be used recently in foods (Katayama, 1976 ; Yamaguchi et al., 1977).

It seems that more study on the chronic toxicity of carminic acid should be done, judging from the reports that the anthraquinone moiety of carminic acid is structurally similar to luteoskyrin, a fungal metabolite, with a known pattern of hepatotoxic activity (Drake, 1975), and that lithium salt of carminic acid provoked a slight teratogenic effect (Schlüter, 1971).

On the other hand, capsanthin and crocin " $\mathrm{B}$ " were considerably toxic among the natural food dyes extracted from plants. But crocin " $\mathrm{A}$ " extracted from the same origin as crocin " $\mathrm{B}$ " was not toxic.

The purification of natural food dyes is difficult because of technical and economical problems, and it has been noted that their properties change readily after purification (Katayama, 1974). The present study suggested that natural food dyes were well separated by HPLC. Analyses of carminic acid and crocin by HPLC indicated that there existed some differences in elution patterns between the commercial preparations. However it was difficult to identify the toxic fraction of the dye using this type of HPLC. Therefore it was impossible to explain the difference in toxicity between the commercial preparations from the same origin such as carminic acid " $A$ " and " $B$ ", or crocin " $A$ " and " $\mathrm{B}$ ". The use of preparative type-HPLC is recommended to purify these dyes and identify their toxicities.

Since the relation between the toxic effect of natural food dyes on $\mathrm{Pc}$ and the inhibitory effect of dyes on LAP, acid phosphatase and esterase which play important roles in the digestive process was observed, the same mechanism of toxicity might be one of the lethal factors as in the case of tar food dyes. Laccaic acid "B" and carminic acid "A" also inhibited $\gamma$-GTP activity completely. It was assumed that the toxicity of these dyes had some relations with both the digestive process of Pc and the amino acid transport of the Pc cells.

Natural food dyes will be used more frequently in the future, but it seems that there are many problems regarding the acute or chronic toxicity of natural food dyes. The present study indicated that several natural food dyes employed in Japan were toxic to $\mathrm{Pc}$. Whether or not the toxic effect of these dyes on $\mathrm{Pc}_{\mathrm{c}}$ is related to the acute or chronic toxicity in mammalian tissues is an interesting problem. 


\section{SUMMARY}

The toxicity of 14 commercial natural dyes which are widely used as food additives in Japan was studied in Paramecium caudatum. Laccaic acid and capsanthin were found to be very toxic to Paramecium caudatum. Some of the commercially available carminic acid and crocin were also toxic. The effect of natural food dyes on leucine aminopeptidase, acid phosphatase, $\gamma$-glutamyl transpeptidase and esterase activity extracted from Paramecium caudatum was studied in order to investigate the mechanism of toxicity. The inhibitory effect of natural food dyes on leucine aminopeptidase, acid phosphatase and esterase in vitro was well proportional to the toxic effect of the dyes on the survival time of Paramecium caudatum. The low concentration of laccaic acid " $\mathrm{B}$ " and carminic acid " $\mathrm{A}$ " inhibited $\gamma$-glutamyl transpeptidase activity completely. The purity of the commercial natural food dyes were analyzed by high performance liquid chromatography and the possible difference in toxicity was discussed in relation to the components.

\section{ACKNOWLEDGMENT}

This study was supported in part by a scientific research grant from the Hokkaido Prefecture, Japan.

\section{REFERENCES}

Allen, S.L., Misch, M.S., and Morrison, B.M. (1963 a). Variations in the electrophoretically separated acid phosphatases of Tetrahymena. J. Histochem. Cytochem. 11, 706-719.

Armstrong, J.M., Myers, D.V., Verpoortl, J.A., and Edsall, J.T. (1966). Purification and properties of human erythrocyte carbonic anhydrases. J. Biol. Chem. 241, 5137-5149.

Cairns, J., Beamer, T., Churchill, S., and Ruthven, J. (1971). Response of protozoans to detergentenzyme. Hydrobiologia 38, 193-205.

Drake, J. J. P. (1975). Food colours-harmless aesthetics or epicurean luxuries? Toxicol. 5, 3-42.

Esteve, J.C. (1970). Distribution of acid phosphatase in Paramecium caudatum. J. Protozool. 17, 24-35.

Joan, S.S. (1974). Age-correlated effects of caffeine on nonirradiated and UV-irradiated Paramecium aurelia. J. Gerontol. 29, 256-260.

Katayama, O. (1974). Color additives for food. J. Synth. Org. Chem. 32, 620-631.

Katayama, O. (1976). New food additives. J. Oil Chem. Soc. 25, 183-189.

Kokia, I.Y. (1971). Sensitivity of Paramecium caudatum to the action of lethal concentrations of sodium 2, 4-D. Eksp. Vod. Toksikol. 2, 43-48.

Orlowski, M., and Meister, A. (1970). The gamma-glutamyl cycle: A possible transport system for amino acid. Proc. Nat. Acad. Sci. USA 67, 1248-1255.

Reiss, J. (1971). Der einflu $\beta$ von Aflatoxin B, auf Paramecium caudatum und Paramecium bursaria. Arch. Hyg. 154, 533-536.

Rowe, E., Gibson, I., and Cavill, A. (1971). The effects of growth conditions on the esterases of Paramecium aurelia. Biochem. Genet. 5, 151-159.

Sako, F., Kobayashi, N., Taniguchi, N., Honma, H., Saito, K., and Takakuwa, E. (1976). Toxic effects of food dyes on Paramecium caudatum. Jap. J. Hyg. 31, 223. 


\section{Fumiyo SAKO et al.}

Sako, F., Taniguchi, N., Kobayashi, N., and Takakuwa, E. (1977). Effect of food dyes on Paramecium caudatum. Toxicol. Appl. Pharmacol. 39, 111-117.

Schlüter, G (1971). Time-response-relationship of embryotoxic effects of lithium carmine in mice. Arch. Exptl. Pathol. Pharmakol. 270, 316-318.

Takakuwa, E., Saito, K., Kamori, K., Yatake, M., Honma, H., and Saito, M. (1971). Studies on the determination of drug toxicity. Jap. J. Pub. Health. 18, 459-461.

Tanaka, K., and Okahara, K. (1973). Effects of food additives on alimentary tract. J. Food Hyg. Soc. 14, 234-238.

Taniguchi, N., Saito, K., and Takakuwa, E. (1975). $\gamma$-Glutamyl transferase from azo dye induced hepatoma and fetal rat liver. Biochim. Biophys. Acta 391, 265-271.

Yamaguchi, 'T., Sakagami, M., Taguchi, H., Yoshida, Y., and Arai, T. (1977). Hygienic studies on the actual conditions of natural additives in foods. Res. Food Sanit. 27, 327-333. 